\section{The role of clinical guidelines in establishing competent professional practice}

CPD

David Pakchung, Morag Smith, Catherine Hughes

\section{Background}

In a medical negligence claim, courts must consider whether a doctor acted in accordance with the required standard of care. Experts may disagree on what should have been done, particularly in light of knowledge that a patient has been harmed. In Australia, the law gives further guidance on the standard of care, providing that doctors will not have breached their duty if they acted in a manner that, at the time the service was provided, was widely accepted by peer professional opinion as competent professional practice.

\section{Objectives}

The aim of this paper is to provide guidance to doctors on how practice in accordance with college, hospital or other accepted professional guidelines is likely to be viewed by a court in the event of a professional negligence claim.

\section{Discussion}

In two recent cases, courts in different states have considered the role of professional guidelines in establishing what was widely accepted as competent professional practice.
In Ellis v East Metropolitan Health Service, it was alleged that a child was left with neurological and physical impairment as a result of traumatic vacuum extraction, performed negligently by a general practitioner (GP) obstetrician. ${ }^{1}$ In determining the appropriate standard of care, the judge considered guidelines issued by the Royal College of Obstetricians and Gynaecologists, the Royal Australian and New Zealand College of Obstetricians and Gynaecologists and King Edward Memorial Hospital in WA (hereafter collectively referred to as the $O \& G$ guidelines), which set out the situations in which an instrumental delivery should be performed, and the circumstances in which it should be abandoned. ${ }^{1}$

The court found the GP obstetrician was negligent in attempting an instrumental delivery in the ward rather than in an operating theatre, when the fetal head was mid-cavity and had not descended for four hours, and in failing to abandon the attempted instrumental delivery after the third pull of the Kiwi cup, ${ }^{1}$ contrary to the O\&G guidelines.

In Gould v South Western Sydney Local Health District, the injured patient was a boy aged eight years whose thumb had to be amputated after it developed gangrene. ${ }^{2}$

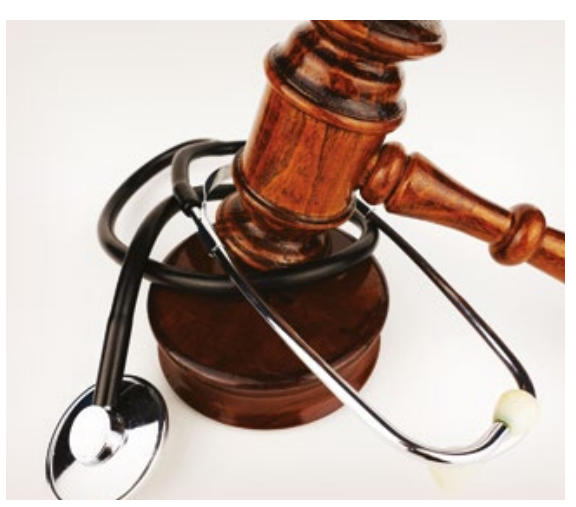

Robert Gould presented for treatment for a compound fracture to his left thumb. He told staff at the hospital that he had slipped and fallen on a wet concrete floor. It only emerged much later that he had been playing in a canal drain when he had slipped and his hand was crushed by a rock.

The judge in the original trial rejected the hospital's argument that the antibiotics (a penicillin derivative and a cephalosporin) given to Robert in accordance with the 14th edition of the Therapeutic guidelines - Antibiotic publication (the Antibiotic Guidelines) were appropriate. He preferred expert opinion that gentamicin should have been administered as an appropriate therapy for this type of injury. He ruled the failure to administer gentamicin caused Robert to develop the infection that resulted in osteomyelitis and gangrene and ultimately the loss of his thumb. ${ }^{2}$

\section{The law}

The law differs between states, ${ }^{3}$ but broadly provides that a health professional will not have breached their duty of care if they acted in a manner that, at the time the service was provided, was widely accepted by peer professional opinion as competent professional practice. The provisions generally recognise that there 
may be differing professional opinions, and that to be 'widely accepted', peer professional opinion does not need to be universally accepted.

The test is a peer test, so the court is to be guided by expert opinion about the appropriate standard of care.

The court in the Ellis case specifically considered the meaning of "widely accepted' ${ }^{1}$ and agreed with an earlier decision in which the judge had clarified that the expression should have its ordinary meaning, that is:

\section{If a large group of the health professional's peers regard the practice as representing competent medical practice, then the practice is widely accepted. A practice which is eccentric, or idiosyncratic, or experimental, or 'alternative', does not fall within the definition of widely accepted practice.}

\section{But a widely accepted practice need not be universally accepted ... There might be two or more schools of thought, or two or more treatment options, both or all of which might be accepted as representing competent medical practice, ... each option is capable of being widely accepted as representing competent medical practice although individual practitioners might choose one over the other. ${ }^{4}$}

\section{The role of guidelines in establishing appropriate practice}

Recent court decisions have raised technical issues around the interpretation of the phrase 'competent professional practice' within the legislative provisions. ${ }^{5,6}$ This is a debate about whether 'practice' means the general practice of the profession or a particular, specific practice or method of providing the service.

While this legal debate continues, it is clear from these cases that where there are applicable guidance documents such as guidelines or protocols, they will be considered evidence of the existence of accepted professional practice and the appropriate standard of care. ${ }^{5}$ They are often important evidence when expert opinion differs significantly on the care that should have been provided.
However, guidelines will not necessarily be determinative of the standard of care required. The value of any guidelines as evidence will depend on satisfying the court of their acceptance and use by clinicians and applicability to the circumstances. ${ }^{7}$ In a medical negligence case, if there are guidelines that apply to the clinical situation and a party wishes to rely on them in the case, the guidelines will be referred to in the expert opinion filed on the party's behalf in the proceedings.

There is a qualification: the court is not required to follow expert opinion about the accepted standard of care if the court considers the opinion to be "irrational' ${ }^{8}$ or if the practice is unreasonable. ${ }^{9}$ It was this 'irrationality' element that caused particular consternation in the Gould decision.

\section{Application of guidelines}

The courts have not always distinguished between the way in which guidelines and protocols or other guidance documents ought to be applied.

In the Ellis case, the court accepted the $O \& G$ guidelines as evidence of practice widely accepted by the GP obstetrician's peers as competent professional obstetric practice. Failure to act in accordance with the guidelines led to a finding of negligence.

At the trial in the Gould case, both parties' experts agreed that gentamicin did not appear in the Antibiotic Guidelines' recommendations for treatment of compound (open) fractures. However, they differed on how closely guidelines ought to be adhered to.

The judgement summarised the expert's argument for the plaintiff as being that the clinician should take guidelines into consideration but use clinical judgement to determine the appropriate antibiotic regimen on a case-by-case basis. Guidelines, according to this view, were not 'protocols which are adhered to slavishly, as in a box-ticking exercise'. ${ }^{2}$ On the other hand, the defendant's expert contended that the principles of antibiotic stewardship meant that it was important to have standard treatment regimens nationally to help avoid the development of antibiotic resistance. ${ }^{2}$ On this view, close adherence to guidelines was essential to avoid practice 'according to whims'. ${ }^{2}$

The trial judge preferred the views of the plaintiff's experts and considered that the opinion of the hospital's experts 'should be seen as being irrational because it was based on unsound reasons'. ${ }^{2}$

On appeal, the Court of Appeal found that the trial judge had misapplied the legal test. The court's job of resolving conflict between competing expert opinions is not the same as determining whether an opinion is irrational. ${ }^{5}$

The Court of Appeal confirmed that there can be more than one body of widely held peer professional opinion. These can be inconsistent without either of them necessarily being irrational. 'Adherence to any of those bodies of peer professional opinion - so long as it is widely accepted in Australia - would render a professional defendant not liable. ${ }^{5}$

The Court of Appeal also considered when a court can discount peer professional practice as irrational, and was clear that this should not be done lightly.

It is a seriously pejorative and exceptional thing to find that a professional person has expressed an opinion that is 'irrational', and even more exceptional if the opinion be widely held. To consider a body of opinion to be 'irrational' is a stronger conclusion than merely disagreeing with $i t$, or preferring a competing body of peer professional opinion. ${ }^{5}$

In this case, the evidence had established that the practice stated in the Antibiotic Guidelines was widely held across Australia and accepted by peer professional opinion as competent. The antibiotics had been administered in accordance with a regimen supported by the Antibiotic Guidelines. Therefore, the health practitioners were not negligent.

The Court of Appeal did confirm that it remained open for a court to find that an opinion is irrational, even if it is accepted by peers as competent practice. The Court of Appeal referred back to the original parliamentary debates around this provision - in which it was contemplated that professional opinion 
could be so out of step with community standards as to require the courts to step in. ${ }^{10}$ One example discussed at the time was a research program where women with positive Pap smear results were left untreated to see whether they would develop invasive cancers. ${ }^{10}$

This is not to say clinical practice guidelines should be followed slavishly. There may be circumstances where it is not appropriate to follow relevant guidelines in a particular patient's case. If guidelines are to be departed from, it is important to consider and document carefully the reasons why they were not followed. A clinician departing from the guidelines should be satisfied that their peers would accept that a departure from the guidelines is competent professional practice in the circumstances. This would allow a clinician to justify their actions if questioned in future.

The judgements in Ellis and of the Court of Appeal in Gould confirm that appropriate adherence to college, hospital or other accepted professional guidelines will be persuasive evidence that the doctors were practising in accordance with widely held peer professional opinion in defence of a medical negligence claim.

\section{Authors}

David Pakchung MBBS, FRACMA, Dip RACOG, MHA, GCAppLaw, Head of Practice Claims (QId), Avant, QId

Morag Smith BJuris, LLB, senior solicitor, Avant, WA Catherine Hughes BA (Hons), LLB (Hons),

MA (Communications), advocacy communications manager, Avant, NSW. Catherine.Hughes@

avant.org.au

Competing interests: None.

Funding: None.

Provenance and peer review: Commissioned, externally peer reviewed.

\section{References}

1. Ellis v East Metropolitan Health Service [2018] WADC 36.

2. Gould v South Western Sydney Local Health District [2017] NSWDC 67.

3. Civil Liability Act 2002 (NSW), s 50; Civil Liability Act 2003 (QId), s 22; Civil Liability Act 1936 (SA), s 41; Civil Liability Act 2002 (Tas), s 22; Wrongs Act 1958 (Vic), s 59; Civil Liability Act (WA), s 5PB; the common law applies in ACT and NT.

4. Wright v Minister for Health [2016] WADC 93 at 85.

5. South Western Sydney Local Health District v Gould [2018] NSWCA 69.

6. Hobson v Northern Sydney Local Health District [2017] NSWSC 589 at 160.
7. Dwyer P. Legal implications of clinical practice guidelines. Med J Aust 1998; 169(6): 292-93. Available at www.mja.com.au/ journal/1998/169/6/legal-implicationsclinical-practice-guidelines [Accessed 18 September 2018].

8. Civil Liability Act 2002 (NSW), s 50; Civil Liability Act 2003 (QId), s 22; Civil Liability Act 1936 (SA), s 41; Civil Liability Ac 2002 (Tas), s 22.

9. Wrongs Act 1958 (Vic), s 59; Civil Liability Act (WA), s 5PB.

10. Ipp DA, Cane P, Sheldon D, Macintosh, I. Review of the law of negligence: Final report. Canberra: Commonwealth of Australia, 2002. Available at https://static.treasury.gov.au/uploads/ sites/1/2017/06/R2002-001_Law_Neg_Final.pdf [Accessed 18 Sep 2018]. 